\title{
Seven Suggestions for Teaching Quantitative Methods
}

Elina Schleutker, University of Freiburg, Germany

ABSTRACT With the increase of data availability, knowledge about quantitative methods is more important than ever. Indeed, students need quantitative methods to understand quantitative academic research, to conduct this research themselves, and to increase their employability in the labor market. Yet, students often experience quantitative methods as difficult to learn and, in turn, instructors find the topic difficult to teach. To make both learning and teaching easier, this article provides seven concrete suggestions regarding the teaching of quantitative methods.

1 $t$ is not surprising that students experience quantitative methods courses as difficult. Indeed, the learning goals of quantitative methods courses (i.e., applying, analyzing, evaluating, and creating) are, in terms of Bloom's Taxonomy (Krathwohl 2002), complex and cognitively demanding. The difficulties experienced in learning have generated a vast literature that provides suggestions for how to better teach quantitative methods (Bailey 2019; Buchler 2009; Fisher and Justwan 2017). This article joins this literature by making seven concrete suggestions. The paper is informed by the academic literature on the topic, my own trial-and-error experiences from teaching undergraduate courses, numerous course evaluations, and discussions with students and colleagues.

\section{\#1: ADDRESS THE NEGATIVE EMOTIONS AND PROVIDE ASSURANCE}

Students' emotions have consequences for learning (Quinlan 2016). Unfortunately, many students who enroll in quantitative methods courses experience statistics anxiety (Zeidner 1991) or research-methods anxiety (Papanastasiou and Zembylas 2008). These anxieties can arise from various sources, which may be dispositional (e.g., perfectionism and level of self-esteem), situational (e.g., prior knowledge and course grade), and environmental (e.g., gender, race, and learning styles). It is not surprising that anxiety can have a negative impact on students' performance (for a review, see Onwuegbuzie and Wilson 2003). Consequently, several strategies to address these negative emotions have been suggested, from the use of humor to reflective journaling (Onwuegbuzie and Wilson 2003, 202-205; Papanastasiou and Zembylas 2008, 165; Waggoner-Denton 2018).

Elina Schleutker (D) teaches comparative politics and governance at the University of Freiburg, Germany. She can be reached at elina.schleutker@politik.uni-freiburg.de.
The number of studies about students' negative feelings toward quantitative methods suggests that it is important for instructors to address these emotions. I have found it helpful to discuss the negative emotions in the first class session. I give students examples of the negative feelings that they may experience (e.g., frustration, stress, and shame) and situations when these feelings may arise (e.g., R-code not working because of a minor mistake, such as forgetting a comma). Moreover, I discuss the reasons why these negative feelings may arise, such as learning something new is always uncomfortable and the course is cognitively demanding. After discussing these aspects, I emphasize the fact that the course will be rewarding and empowering because they will learn to conduct their own quantitative studies, read regression tables in academic papers, and gain tools to reflect critically on the methodology that is applied in quantitative studies.

By addressing the negative emotions at the beginning of the course, I aim to (1) manage students' expectations about the course and hence their motivation and learning; (2) provide reassurance by letting them know that negative emotional responses are common; (3) warn them about the negative emotions so that they will not be overwhelmed and discouraged when they experience them; (4) create an atmosphere in which they are not afraid to ask questions and where they do not feel ashamed or discouraged when the solution to their problems seems trivial (e.g., changing a comma to a period in their R-code); and (5) convince students that even though during the course there often is no instant gratification, their hard work will pay off and they will experience delayed gratification.

\section{\#2: SOFTWARE SELECTION: USE R/RSTUDIO}

Despite the importance of software in quantitative methods courses, there is surprisingly little discussion about software selection and its influence on learning (but see, e.g., Counsell 
and Cribbie 2020). As pointed out by Ward (2013), different software has various advantages and disadvantages, and the software selection ultimately depends on issues such as knowledge of the teacher, a university's software licenses, placement of the course in the overall curriculum, and duration and time frame author states about a topic (e.g., what Marx writes about capitalism), in the methods course, the focus is on various methods. Thus, there are no mandatory readings (which deemphasizes the importance of any one author) but rather several suggested readings from which to choose. Moreover, I encourage my students to use

\section{The number of studies about students' negative feelings toward quantitative methods suggests that it is important for instructors to address these emotions. I have found it helpful to discuss the negative emotions in the first class session.}

of the course. For a long time, I opted to use Excel, SPSS (or PSPP), or R Commander to ensure that students would focus less on the software and more on the methods and their application. In retrospect, this might have been a mistake. Indeed, although R/RStudio in the beginning is more challenging to use than, for example, SPSS, there are many benefits that make it a suitable program for teaching purposes.

First, it is easy to modify the code, which encourages experimentation and the potential for students to understand how changes in the code influence results. Second, the use of $\mathrm{R}$ script and $\mathrm{R}$ Markdown, in particular, makes it easy to add notes directly in the code to document the different steps that have been taken; it also allows for more extensive notes (e.g., the reasons why these steps were taken and the interpretation of the results). Third, $\mathrm{R}$ makes collaborative learning easy because students can easily share their code with one another.

The instructor also can use these properties. For example, I have found it helpful to create a Markdown document for each lab session. The Markdown should be prepared before class, but it also is easy to integrate the class discussions in the Markdown (e.g., when a student suggests another code to address a problem). Similarly, if something in the Markdown is unclear, it is easy to add extensive comments for clarification during or after class. After class, I share the Markdown with the students, which gives them the opportunity to review the material at their own pace. All of this would be difficult with Excel and SPSS because these programs require the instructor to demonstrate how the calculations are performed. These demonstrations cannot be retrieved after class. Alternatively, it is possible to document each step by taking screenshots and adding them to slides. However, slides take a long time to create and are difficult for students to work with after class.

\section{\#3: TEACH STUDENTS TO TEACH THEMSELVES}

A key insight of learner-centered teaching is to shift more responsibility to students and to emphasize learning instead of teaching. Thus, according to the learner-centered teaching paradigm, the instructor's role is to facilitate learning and design appropriate activities for learning purposes rather than "spoon-feed" students the information. In learner-centered teaching, independent learning is encouraged and the content is taught not only for its own sake but also to teach learning skills (Weimer 2002). Therefore, it is important to make students aware of the fact that they can and should teach themselves. In addition, it is important to provide them with suggestions about how to do so.

Regarding the content, I tell students that whereas in the social sciences it often is important to understand what a particular search engines to find additional material (e.g., instructional videos and homepages) that facilitate their understanding of the discussed methods. In this way, students have a solid base of information (i.e., class notes and suggested readings) to which they can refer and they also are made aware of how they can actively contribute to their learning by finding more information.

I apply a similar approach to the understanding of the software. For example, if I know that an answer to a question is easy and only one online search away, or when students ask for my help to interpret error codes in $\mathrm{R}$, I often refuse to give the answer and encourage them to find it on their own. Furthermore, I stress that my code may not be the most elegant solution to a problem and I encourage them to find their own solutions. For example, I design group activities in which students must find a way to perform a calculation that I have not taught them. To ensure that everyone can begin properly, however, it is important to provide enough time and instructor (and/or TA) support at the beginning of the course to address the most basic problems related to the software and the code.

My experience is that the sooner students learn that they are not dependent on me, my lecturing, or a particular course reading for their understanding of the topic or the software, they take more responsibility and agency for their own learning. It is interesting that with more responsibility comes more confidence. Moreover, when students take more responsibility to solve problems on their own, it gives the instructor more time to focus on those aspects of the research process that cannot easily be learned from textbooks or online videos (see $\#_{4}$ and $\#_{5}$ ).

\section{\#4: TAKE ENOUGH TIME TO TEACH REGRESSION}

Many undergraduate methods courses include the topic of linear regression and, perhaps consequently, several articles discuss concrete examples and activities that can be used to teach regression (Kuiper 2008; Lindner 2012). Yet, it is important to be aware that "teaching regression" actually comprises several different aspects and, to give students a working knowledge about regression analysis, it is necessary to take enough time to teach each aspect.

First, teaching linear regression means that we introduce the basic mathematics of the method (i.e., interpretation of the regression equation and assumptions of the regression). It is important that students understand these basics; consequently, in addition to my own teaching, I encourage them to actively search for additional resources on the topic (see also \#3).

Second, teaching linear regression means that we show how linear regression is run with the software and discuss the interpretation of the output. My experience is that students struggle 
considerably with the software output-for example, it may be difficult to identify the constant and regression coefficients from the output and understand how these relate to the regression equation. Therefore, it is important for the instructor to take enough time to discuss the software output, especially because information about its interpretation cannot be found easily in other resources. Indeed, textbooks and other resources that explain software output in detail often refer to a particular software and dataset, and it can be difficult for students to understand how this information applies to the software, data, and examples used in the course.

Third, teaching linear regression means that we guide students in reading and interpreting regression results in research papers. For students, the link among the mathematics, software output, and published regression findings is not straightforward. Thus, we cannot expect that because they master the mathematics and the software that they also would automatically understand published regression results. Consequently, it is important to devote at least one class session to this activity. My preferred teaching strategy is to give students two or three regression tables from published research papers and ask them to discuss the interpretation of the results (e.g., identify the dependent and independent variables, the constant, and the regression coefficients). Another exercise, which admittedly is embarrassingly simple but which I have found to be helpful, asks students to create a regression table from the regression output in the software. It does require time to enter the numbers in a spreadsheet, but the exercise increases students' understanding of how the software output and published regression tables are related.
To facilitate students' understanding of methods and research practices, experts on methods teaching recommend a learning-bydoing approach and working with data (Lewthwaite and Nind 2016). Furthermore, several instructors have had positive experiences with teaching quantitative methods with real-life examples (Oldmixon 2018; Rosen 2018; Thompson 1994). These sentiments -that is, students learn by active involvement in learning activities and students learn to do well only what they practice doingare echoed in many of Garfield and Ben-Zvi's (2007) influential principles for learning statistics.

I suggest that using real-life data and teaching data wrangling are beneficial for students' learning. Indeed, although it may be tempting to use ready-made datasets (e.g., those embedded in $\mathrm{R}$ packages) for convenience (e.g., all the required variables are included and the problems with missing data are limited), I caution against this approach. Ready-made datasets typically are neatly organized and cleaned up, whereas the data used in actual research often come from many different sources and are messy. Thus, when using ready-made datasets, we do not teach several important skills that students need in their own research projects -for example, importing data in different formats into R; merging, reshaping, and subsetting datasets; and deleting individual rows and columns. If students do not learn these skills, they may be discouraged from applying quantitative methods. Notice also that although there are several resources that teach basic statistical concepts, information on data wrangling is more difficult to find. Moreover, students need to know some of the vocabulary (e.g., merging, subsetting, and reshaping) in order to know the information for which they should be looking. Therefore, to empower

\section{For students, the link among the mathematics, software output, and published regression findings is not straightforward. Thus, we cannot expect that because they master the mathematics and the software that they also would automatically understand published regression results.}

Fourth, teaching regression analysis means that we help students to apply regression for their own research. It is impossible to completely separate this aspect of teaching regression from the previous three aspects, because considerations about, for example, variable selection arise when the basic mathematics are taught. At the same time, new and unexpected problems typically arise at this stage-for example, the use of dummy variables and how to address missing data and outliers. This stage also requires a learning-by-doing approach, such as teaching students about data wrangling (see $\#_{5}$ ), and requiring them to produce their own research (see \#6).

\section{\#5 TEACH DATA WRANGLING}

Some of the difficulties that students experience in quantitative methods courses are related to superficial teaching, difficulty in understanding the link between theory and practice, and unfamiliarity and difficulty with the concepts and content (Murtonen and Lehtinen 2003). As summarized by Murtonen and Lehtinen (2003, 179), "Books and abstract examples by teachers were not enough to create a deep understanding of concrete research procedures. A lack of real need for the methods did not encourage learning." students to conduct their own research, it is essential to teach at least some data wrangling.

Perhaps one of the best ways to teach data wrangling is to ask students to replicate selected parts of a quantitatively oriented study (e.g., studies with country-level data are suitable because most of the data are freely available online). Indeed, replication of a study should clarify the payoff of data wrangling because students may experience its teaching without context as boring and meaningless. To prepare for the replication exercise, I assign the paper that we replicate as a mandatory reading and ask students to give particular attention to the methodology section. During class, I then ask-based on the description in the methodology section-how we should start with the replication and what different steps we should take. Because students are not used to reading methodology sections as a practical guide, it typically takes considerable time for them to understand what should be done first (the instructor may provide scaffolding questions on the reading to support this process). Similarly, it takes a long time to find and download the needed datasets. Moreover, several problems arise regarding the replication-for example, datasets have more variables than what are needed for the purposes of the 
replication and datasets may come in formats such as sav or dta and cannot be opened in $\mathrm{R}$ without difficulty.

Although it takes considerable time to review the different steps of replication, students give positive feedback regarding this exercise, which appears to enhance their understanding of the research process. From my perspective, the exercise has several benefits. First, students learn valuable skills that they need in their which they are confronted. The presentations make it easy for the instructor to provide feedback on the projects. Because students want to avoid mistakes in their final papers, instructor feedback on the presentations typically is incorporated and thus more beneficial for students' learning than feedback only on the final product. Moreover, because many students struggle with similar problems, comments by the instructor are likely to be beneficial for several

\section{Perhaps one of the best ways to teach data wrangling is to ask students to replicate selected parts of a quantitatively oriented study.}

own research. Second, the confidence of students increases as they realize that they are equipped to conduct basic research (i.e., they can do the same research as the authors of a published research paper). Third, the motivation of students toward quantitative methods increases as they realize that much interesting data are freely available for them to use. Fourth, students learn about the importance of writing a clear and detailed methodology section; studies that include inadequate methodology descriptions are difficult to replicate.

\section{\#6: USE COURSE ASSESSMENT TO ENCOURAGE LEARNING}

The literature concludes that assessment has the potential to influence both student learning and their approaches to learning (for a critical discussion, see Joughin 2009). Ideally, then, assessment in quantitative methods courses should align with the learning objectives, supporting deep learning and transferability of the knowledge to other contexts. To achieve these goals, I have found it helpful to use assessment formats that are application oriented.

The first type of assessment is based on the idea of critical evaluation of a published research paper that uses linear regression as a method. I provide students with a choice of two or three academic articles. Preselection is essential because it allows me to offer articles that I know well (which makes it easier to give feedback on the assignments) and that correspond to students' methodological knowledge. For all of the articles, I give students a set of questions that they must answer. These questions require them to provide information and assess the different methodological steps, such as operationalization of the central theoretical concepts and presentation of the regression results. Overall, the assignment requires students to apply knowledge that they have learned during the course.

The second type of assessment requires students to conduct their own research on a topic that they can approach using OLS regression. They are free to decide on the topic based on their own interests, but I also provide suggestions and feedback regarding their choice. To ensure that students are not overwhelmed by the task, I provide strict guidelines regarding the structure of the paper and the methodological steps that I expect them to discuss (e.g., potential problems with missing data, multicollinearity, and heteroscedasticity).

Before students submit their final paper, they give a presentation about the project. To relieve the anxiety that some students may feel regarding the project (see $\#_{1}$ ), the presentations are not graded. I explicitly ask them to give a presentation of the current state of their research, preferably focused on the problems with students. Finally, it often is reassuring for students to notice that their peers are struggling with similar methodological problems.

\section{\# 7: FOCUS ON TRADEOFFS; AVOID THE COOKBOOK APPROACH}

As pointed out by Buchler $(2009,529)$, many students aim to apply a "cookbook approach"-that is, they "have internalized the belief that getting through a math class means recognizing which technique a problem requires and applying it by rote. Hence, they find themselves checking their mental cookbooks to see whether they are supposed to use a t-test or a chi-square test on question 3. When students take this approach, they are not truly learning research methods. They are learning to mimic research methods." To overcome the cookbook-approach problem, Buchler (2009) recommended that methods courses be organized around practical research problems rather than techniques.

Yet, even in problem-oriented courses, the cookbook approach easily creeps in regarding details about the methodological decisions that can be made in a research project. For example, students often ask how they should address missing data, treat outliers, and whether they should use standardized or unstandardized regression coefficients. In other words, students expect me to give them the correct answer, the one recipe, that they always can use. To wean students from the cookbook approach and teach the importance of personal judgment regarding methodological decisions, I try to find time for extensive discussions about these questions whenever they arise. Students often are actively engaged in these discussions and offer several good suggestions as to how the problems (e.g., missing data) can be solved.

Through these discussions, it is hoped that students will learn that there usually is more than one way to solve a problem and that the different solutions also have different consequences for the results. In other words, the discussions should encourage students to discover the tradeoffs as well as the advantages and disadvantages of different solutions. In this regard, I find the cookbook metaphor to be helpful in explaining the research process: an experienced cook will not automatically follow a recipe and add the suggested amount of salt but rather understands how the taste of the dish is influenced by adding more or less salt than the recipe recommends.

\section{REFERENCES}

Bailey, Michael A. 2019. “Teaching Statistics: Going from Scary, Boring, and Useless to, Well, Something Better." PS: Political Science \& Politics 52 (2): 367-70.

Buchler, Justin. 2009. “Teaching Quantitative Methodology to the Math Averse.” PS: Political Science \& Politics 42 (3): 527-30. 
Counsell, Alyssa, and Robert A. Cribbie. 2020. "Students' Attitudes toward Learning Statistics with R." Psychology Teaching Review 26 (2): 36-56.

Fisher, Sarah, and Florian Justwan. 2017. "Scaffolding Assignments and Activities for Undergraduate Research Methods.” Journal of Political Science Education 14 (1): $63-71$.

Garfield, Joan, and Dani Ben-Zvi. 2007. "How Students Learn Statistics Revisited: A Current Review of Research on Teaching and Learning Statistics.” International Statistical Review 75 (3): 372-96.

Joughin, Gordon. 2009. "Assessment, Learning, and Judgment in Higher Education A Critical Review." In Assessment, Learning, and Judgment in Higher Education, ed. Gordon Joughin, 13-27. The Netherlands: Springer.

Krathwohl, David R. 2002. “A Revision of Bloom's Taxonomy: An Overview.” Theory into Practice 41 (4): 212-18.

Kuiper, Shonda. 2008. "Introduction to Multiple Regression: How Much Is Your Car Worth?" Journal of Statistics Education 16 (3). https://doi.org/10.1080/ 10691898.2008.11889579.

Lewthwaite, Sarah, and Melanie Nind. 2016. "Teaching Research Methods in the Social Sciences: Expert Perspectives on Pedagogy and Practice." British Journal of Educational Studies 64 (4): 413-30.

Lindner, Andrew M. 2012. "Teaching Quantitative Literacy through a Regression Analysis of Exam Performance." Teaching Sociology 40 (1): 50-59.

Murtonen, Mari, and Erno Lehtinen. 2003. "Difficulties Experienced by Education and Sociology Students in Quantitative Methods Courses." Studies in Higher Education 28 (2): 171-85.
Oldmixon, Elizabeth A. 2018. "'It Was My Understanding That There Would Be No Math': Using Thematic Cases to Teach Undergraduate Research Methods." Journal of Political Science Education 14 (2): 249-59.

Onwuegbuzie, Anthony J., and Vicki A. Wilson. 2003. "Statistics Anxiety: Nature, Etiology, Antecedents, Effects, and Treatments-A Comprehensive Review of the Literature." Teaching in Higher Education 8 (2): 195-209.

Papanastasiou, Elena C., and Michalinos Zembylas. 2008. "Anxiety in Undergraduate Research Methods Courses: Its Nature and Implications." International Journal of Research \& Method in Education 31 (2): 155-67.

Quinlan, Kathleen M. 2016. "How Emotion Matters in Four Key Relationships in Teaching and Learning in Higher Education." College Teaching 64 (3): 101-11.

Rosen, Amanda M. 2018. "The Best Breakfast in Town: A Comprehensive Research Methods Project." PS: Political Science \& Politics 51 (1): 173-77.

Thompson, W. Burt. 1994. "Making Data Analysis Realistic: Incorporating Research into Statistics Courses." Teaching of Psychology 21 (1): 41-43.

Waggoner-Denton, Ashley. 2018. "The Use of a Reflective Learning Journal in an Introductory Statistics Course." Psychology Learning \& Teaching 17 (1): 84-93.

Ward, Brian W. 2013. "What's Better-R, SAS, SPSS, or Stata? Thoughts for Instructors of Statistics and Research Methods Courses." Journal of Applied Social Science 7 (1): 115-20.

Weimer, Maryellen. 2002. Learner-Centered Teaching: Five Key Changes to Practice. San Francisco: Jossey-Bass, Inc.

Zeidner, Moshe. 1991. "Statistics and Mathematics Anxiety in Social Science Students: Some Interesting Parallels." British Journal of Educational Psychology 61:319-28. 